\title{
Les vulnérables : evaluating the vulnerability criterion in Article 14 cases by the European Court of Human Rights
}

\author{
So Yeon $\mathrm{Kim}^{\star}$ \\ St Edmund's College, University of Cambridge, Cambridge, UK \\ *Author email: syk31@cam.ac.uk
}

(Accepted 21 March 2021)

\begin{abstract}
The European Court of Human Rights (the Court) has been invoking the vulnerability criterion to overcome the drawbacks of cases concerning Article 14 of the European Convention on Human Rights, the prohibition of discrimination. This new criterion, allowing the Court to favour the applicants, highlights the applicants' group affiliation. However, whether this criterion is effective in protecting vulnerable applicants against discrimination is doubtful. To examine this, I divide the Court's approach to Article 14 before and after the application of the vulnerability criterion. I argue that vulnerability criterion was used to fix the drawbacks of Article 14, but eventually backfired. The concept of vulnerability has been ambiguous, inconsistently used by the Court, and paternalistic. I suggest the Court focus on individual autonomy rather than grouping the applicants to improve their legal reasoning of Article 14.
\end{abstract}

Keywords: human rights; vulnerable groups; vulnerability; discrimination; European Convention on Human Rights; European Court of Human Rights

\section{Introduction}

In October 2019, the European Court of Human Rights (the Court) released a landmark decision, $J D$ and $A v$ the United Kingdom. The Court ruled the UK's 'bedroom tax' to be discriminatory under Article 14 of the European Convention on Human Rights (ECHR). 'Bedroom tax' is a nickname for the provisions introduced by the Housing Benefit (Amendment) Regulations 2012, which reduce a claimant's housing benefit if their home has a spare room. ${ }^{2}$ Applicant $\mathrm{A}$, in this case, was living with her son in a three-bedroom house and was under the social protection of the 'Sanctuary Scheme' due to severe domestic violence. With the help from the Sanctuary Scheme, applicant A modified her attic into a 'panic room' in order to retreat in times of danger. However, the UK levied the bedroom tax on this spare room, and reduce applicant A's housing benefit by $14 \%{ }^{3}$

In this case, the fact that the applicant had a vulnerable status, as a victim of domestic violence, was the key turning point. When an applicant is particularly vulnerable, this reduces the respondent state's margin of appreciation and requires the respondent state to give weighty reasons for the differential treatment. ${ }^{4}$ The UK failed to reasonably justify its levying of the bedroom tax on applicant A despite the necessity of her having a spare room. Hence, the Court ruled that the UK violated Article 14, the

\footnotetext{
${ }^{1}$ Convention for the Protection of Human Rights and Fundamental Freedoms (adopted 4 November 1950, entered into force 3 September 1953) 213 UNTS 221; ETS 5.

${ }^{2} J D$ and $A v$ the United Kingdom Application Nos 32949/17 and 34614/17, Merits and Just Satisfaction, 24 October 2019, at [9], [32].

${ }^{3}$ Ibid, at [12], [13].

${ }^{4}$ Ibid, at [89].

(C) The Author(s), 2021. Published by Cambridge University Press on behalf of The Society of Legal Scholars. This is an Open Access article, distributed under the terms of the Creative Commons Attribution licence (http://creativecommons.org/licenses/by/4.0/), which permits unrestricted re-use, distribution, and reproduction in any medium, provided the original work is properly cited.
} 
prohibition of discrimination, by levying the bedroom tax on this vulnerable applicant who fell within a 'small and easily identifiable group' (at [105]).

The jurisprudence of Article 14 developed in the direction of expanding the grounds of discrimination, from sex, race, and religion, to sexual orientation and gender identity. However, critics doubted the effectiveness of Article 14 and relevant case law in tackling discrimination against vulnerable and disadvantaged applicants. ${ }^{5}$ Facing these doubts, in 2007 the Court adopted a vulnerability criterion to ensure better protection of applicants in vulnerable positions. Focusing on the vulnerability of the group or the status of the applicant, this approach demands that the respondent state afford 'special protection' to vulnerable groups. ${ }^{6}$ The Court also required higher bars for the respondent states to justify discriminatory treatment.

Notwithstanding this new fix, whether the vulnerability criterion has been effective in protecting vulnerable applicants against discrimination is doubtful. This is alarming, as Article 14 cases amount to 4,252 cases out of approximately 60,000 cases in the Court, almost $10 \%$ of the Court's cases as of May 2021. ${ }^{7}$ Also, the vulnerability criterion has greatly influenced the reasoning and outcome of Article 14 cases. Despite its significance, the vulnerability criterion has seldom been researched in light of its effectiveness in protecting the vulnerable groups. ${ }^{8}$

The concept of vulnerable groups needs to be revisited in light of the Covid-19 crisis, as we now face the new vulnerable groups: those who suffered or are suffering from Covid-19. Of those who survived Covid-19, many are reporting severe after-effects of brain fog, a persistent loss of smell and taste, long-term damage to heart, brain, lungs and kidneys, and so forth. ${ }^{9}$ They have reported severe difficulties in returning to work and daily lives, leading to a question of whether they might later be categorised as a vulnerable group. In certain countries where the identities of Covid patients are revealed, they are being bullied, stigmatised, and marginalised within the regional community. As such, this paper is a novel attempt to analyse the vulnerability criterion with reference to recent case law and situations.

This paper thus examines, from a doctrinal perspective, the Court's use of the vulnerability criterion in adjudicating Article 14 cases. I argue that Article 14 still fails to tackle discrimination against vulnerable and disadvantaged groups, despite the Court's introduction of the vulnerability criterion. First, I briefly explore the Article 14 of the ECHR, prohibition of discrimination. Then, developments in the Court's jurisprudence on Article 14 are examined, looking at the Court's classic approach to Article 14 cases and the rise of the vulnerability criterion (the concept of 'vulnerable groups').

\footnotetext{
${ }^{5} \mathrm{M}$ Cartabia 'The European Court of Human Rights: judging nondiscrimination' (2011) 9 International Journal of Constitutional Law 808; J Gerards 'The discrimination grounds of Article 14 of the European Convention on Human Rights' (2013) 13 Human Rights Law Review 99; A Timmer 'Toward an anti-stereotyping approach for the European Court of Human Rights' (2011) 11 Human Rights Law Review 707.

${ }^{6}$ DH and Others $v$ the Czech Republic Application No 57325/00, Merits and Just Satisfaction, 13 November 2007, at [182].

${ }^{7}$ HUDOC, hudoc.echr.coe.int/eng\#\{\%22article\%22:[\%2214\%22,\%2214+2\%22,\%2214+2-1\%22,\%2214+3\%22,\%2214+4\%22,\% $2214+4-3-\mathrm{d} \% 22, \% 2214+5 \% 22, \% 2214+5-1 \% 22, \% 2214+5-1-\mathrm{a} \% 22, \% 2214+5-1-\mathrm{c} \% 22, \% 2214+5-3 \% 22, \% 2214+5-4 \% 22, \% 2214+6 \%$ $22, \% 2214+6-1 \% 22, \% 2214+6-2 \% 22, \% 2214+6-3 \% 22, \% 2214+6-3-b \% 22, \% 2214+6-3-\mathrm{c} \% 22, \% 2214+7 \% 22, \% 2214+8 \% 22, \% 2214+8-$ $1 \% 22, \% 2214+9 \% 22, \% 2214+9-1 \% 22, \% 2214+10 \% 22, \% 2214+11 \% 22, \% 2214+12 \% 22, \% 2214+13 \% 22, \% 2214+\mathrm{P} 1-1 \% 22, \% 2214+\mathrm{P} 1-$ 1-1\%22,\%2214+P1-2\%22,\%2214+P1-3\%22,\%2214+P4-2\%22,\%2214+P7-1\%22],\%22documentcollectionid2\%22:[\%

22GRANDCHAMBER\%22,\%22CHAMBER\%22]\} (last accessed 10 May 2021). Both the number of total cases and cases involving Art 14 include instances when the case is provided in more than one language.

${ }^{8}$ There are three articles to date which mainly discuss the Court's use of the vulnerability criterion: L Peroni and A Timmer 'Vulnerable groups: the promise of an emerging concept in European Human Rights Convention law' (2013) 11 International Journal of Constitutional Law 1056; OM Arnardóttir 'Vulnerability under Article 14 of the European Convention on Human Rights: innovation or business as usual?' (2017) 4 Oslo Law Review 150; M Baumgärtel 'Facing the challenge of migratory vulnerability in the European Court of Human Rights' (2020) 38 Netherlands Quarterly of Human Rights 12.

${ }^{9} \mathrm{~J}$ Couzin-Frankel 'From “brain fog” to heart damage, Covid-19's lingering problems alarm scientists' Science, 31 July 2020 , available at https://www.sciencemag.org/news/2020/07/brain-fog-heart-damage-covid-19-s-lingering-problems-alarm-scientists\#: :text=The\%20list\%20of\%20lingering\%20maladies,lungs\%2C\%20kidneys\%2C\%20and\%20brain. (last accessed $10 \mathrm{May}$ 2021).
} 
Then, the ineffectiveness of Article 14 is studied, by looking at the situation both before and after the vulnerability criterion, which was first introduced in 2001 and crystallised in 2007. ${ }^{10}$

Before the advent of the vulnerability criterion, the ineffectiveness of Article 14 was due to the 'parasitic' nature of Article 14 and inconsistency within the Court's approaches to Article 14. These factors were amplified, rather than being attenuated, after the vulnerability criterion was introduced. This is due to the ambiguous concept of 'vulnerable groups', incoherent application of the new criterion, and stigmatisation and paternalism which the concept brings. As such, I argue that the ineffectiveness of Article 14 persists even after the Court tried to fix the problem with the vulnerability criterion. To improve the Court's approach on Article 14, I suggest the Court focus on individual autonomy rather than on group affiliation.

\section{Prohibition of discrimination: Article 14}

Article 14 of the ECHR states:

the enjoyment of the rights and freedoms set forth in this Convention shall be secured without discrimination on any ground such as sex, race, colour, language, religion, political or other opinion, national or social origin, association with a national minority, property, birth or other status.

This provision protects the rights and freedoms stated 'in the Convention', which gives the provision a role that is subsidiary to the other substantive provisions. ${ }^{11}$ In other words, the right under Article 14 cannot exist independently unless the factual situation falls 'within the ambit' of the ECHR. ${ }^{12}$ This nature of Article 14 has been described in many ways, from being an 'ambit' requirement to 'parasitic' provision. ${ }^{13}$

The Court interprets discrimination as 'treating persons in analogous situations differently without an objective and reasonable justification'. ${ }^{14}$ The situations do not need to be identical, but relatively similar situations will suffice to meet the condition. ${ }^{15}$ Not all differential treatment will amount to a violation of Article 14, provided that the respondent state can supply an objective and reasonable justification. ${ }^{16}$ Moreover, discrimination does not have to be intentional to result in a violation of Article $14 .{ }^{17}$ Any policies or measures which lead to prejudicial effects in a disproportionate manner on a particular group without hard evidence of discriminatory targeting may suffice. ${ }^{18}$ The Court has also stated that states have a positive obligation to protect people against private discrimination. ${ }^{19}$

The discrimination grounds of Article 14 are open-ended, through the phrase 'or other status' ${ }^{20}$ The Court has confirmed that the provision provides an illustrative and non-exhaustive list. ${ }^{21}$ Although not embodied in the provision, the Court has added other discrimination grounds through case law, such as disability, sexual orientation, professional status, illegitimacy, health, military status, imprisonment, conscientious objection, marital status, and so forth. ${ }^{22}$

\footnotetext{
${ }^{10}$ Chapman $v$ the United Kingdom Application No 27238/95, Merits and Just Satisfaction, 18 January 2001; DH and Others $v$ the Czech Republic, above n 6.

${ }^{11}$ WA Schabas The European Convention on Human Rights: A Commentary (Oxford: Oxford University Press, 2015) p 562.

${ }^{12}$ Ibid; R O'Connell 'Cinderella comes to the ball: Article 14 and the right to non-discrimination in the ECHR' (2009) 29 Legal Studies 211 at 215.

${ }^{13}$ O'Connell, above n 12 , at 212.

${ }^{14}$ Schabas, above n 11, p 564.

${ }^{15}$ Ibid.

${ }^{16}$ DJ Harris et al Law of the European Convention on Human Rights, $3^{\text {rd }}$ edn (2014) p 785.

${ }^{17}$ Schabas, above n 11, p 566.

${ }^{18}$ Ibid.

${ }^{19}$ Harris et al, above n 16, p 786.

${ }^{20}$ Ibid, p 790; Arnardóttir, above n 8, at 154 .

${ }^{21}$ Engels and Others $v$ the Netherlands Application Nos 5100/71, 5101/71, 5354/72 and 5370/72, Merits and Just Satisfaction, 8 June 1976, at [72].

${ }^{22}$ MW Janis et al European Human Rights Law: Text and Materials, $3^{\text {rd }}$ edn (2008) p 471; Harris et al, above n 16, pp 790-791.
} 


\section{Developments in the court's approach to Article 14}

The Court's approach to Article 14 has developed to cope with discrimination against vulnerable groups. Before the vulnerability criterion was applied by the Court, vulnerable groups were dealt with according to the Court's classic approach to Article 14. Even after the introduction of the vulnerability criterion, the Court followed this classic approach, with the vulnerability criterion added. In this sense, this section first explores the Court's classic approach to Article 14 cases. Next, the advent of the vulnerability criterion is discussed, with an examination of the Court's case laws.

\section{(a) The court's classic approach to Article 14 cases}

Based on the text of Article 14, the Court adopts the following process to determine cases. First, the Court examines whether the applicant's case falls within the ambit of other provisions of the ECHR. ${ }^{23}$ If it does, secondly, the Court explores whether there has been differential treatment. In working this out, a comparator approach is often taken. The comparator is usually 'persons in an analogous or relevantly similar situation' to the applicants but without the specific grounds of discrimination in the case. ${ }^{24}$ This is to show that a comparator in relatively similar situations would be treated more favourably than the applicant. ${ }^{25}$ Thirdly, if differential treatment is proved, the respondent state must provide objective and reasonable justifications for the treatment. ${ }^{26}$ Along with the justification, the differential treatment must pursue a legitimate aim, along with proportionality between the means and the ends. ${ }^{27}$ In performing the proportionality test, it is important to discover whether alternative means were available to meet the same ends. ${ }^{28}$

Lastly, the respondent state is given a margin of appreciation in carrying out the objective and reasonable justification test. ${ }^{29}$ The scope of the margin of appreciation depends on the subject-matter, circumstances, and background to the case. ${ }^{30}$ The extent of the margin of appreciation in Article 14 cases varies according to what rights are at stake. When the case involves race, religion, sex or gender, nationality, sexual orientation, or illegitimacy, the Court demands that the respondent state have weighty or particularly serious reasons for differential treatment. ${ }^{31}$ The rationale behind this is that individuals should be protected from states' discriminatory action or inaction against their 'personal characteristics which are beyond their control. ${ }^{32}$ These grounds of discrimination are often termed 'suspect categories', terminology derived from US constitutional law. ${ }^{33}$

On the other hand, when the discrimination grounds are related to characteristics which are issues of choice rather than being innate to personal identity, states are given a wider margin of appreciation. ${ }^{34}$ The burden is commonly on the applicant to convince the Court that the discriminatory treatment has occured. ${ }^{35}$ Also, when the case involves economic or social measures, the Court gives a wide margin of appreciation. ${ }^{36}$ This is because national authorities are generally in a better position to have

\footnotetext{
${ }^{23}$ Harris et al, above n 16, p 785.

${ }^{24}$ European Court of Human Rights Guide on Article 14 of the European Convention on Human Rights and on Article 1 of Protocol No 12 to the Convention (Council of Europe/European Court of Human Rights, 31 August 2020), available at https:// www.echr.coe.int/Documents/Guide_Art_14_Art_1_Protocol_12_ENG.pdf (last accessed 10 May 2021) para 53.

${ }^{25}$ Arnardóttir, above n 8, at 154 .

${ }^{26}$ Ibid.

${ }^{27}$ Schabas, above n 11, p 564 .

${ }^{28}$ Ibid, p 565.

${ }^{29}$ Arnardóttir, above n 8 , at 154 .

${ }^{30}$ Schabas, above n 11, p 567.

${ }^{31}$ Harris et al, above n 16, p 796.

${ }^{32} \mathrm{~A}$ Timmer, 'Bah v UK: on immigration, discrimination and worrisome reasoning', Strasbourg Observers, 12 October 2011, available at https://strasbourgobservers.com/2011/10/12/bah-v-uk-on-immigration-discrimination-and-worrisome-reasoning/ (last accessed 10 May 2021).

${ }^{33}$ Harris et al, above n $16, \mathrm{p} 796$.

${ }^{34} \mathrm{~S}$ Fredman 'Emerging from the shadows: substantive equality and Article 14 of the European Convention on Human Rights' (2016) 16 Human Rights Law Review 273 at 278.

${ }^{35}$ Arnardóttir, above n 8, at 155.

${ }^{36}$ Schabas, above n 11, p 567; Harris et al, above n 16, p 794.
} 
direct knowledge of their societies and their needs than international judges. ${ }^{37}$ Therefore, the Court generally defers to national legislations and policies regarding economic and social issues unless it is 'manifestly without reasonable foundation'. ${ }^{38}$

\section{(b) The rise of the concept of the 'vulnerable groups'}

From the notion of suspect categories, the Court developed a new criterion: vulnerability of the group to which the applicant belongs. ${ }^{39}$ The Court identified negative social attitudes, dependency on the state, historical prejudice, and social exclusion as markers of vulnerable groups. ${ }^{40}$ In contrast to the suspect categories approach, the vulnerability criterion subdivides the most disadvantaged groups within the suspect categories. For example, Roma individuals are identified as part of a vulnerable group although discrimination against them can be broadly categorised as racial discrimination. ${ }^{41}$ By giving special consideration to vulnerable groups, with a focus on the possible effects of a particular rule, the Court intended to encompass substantive equality against structural injustice. ${ }^{42}$

The Court first introduced the notion of vulnerable groups in Chapman $v$ the United Kingdom in 2001. In this case, the Court underlined the minority status of Roma individuals and urged that their cultural diversity be considered in national decision-making processes. ${ }^{43}$ However, the vulnerability criterion did not play a significant role in the judgment, and no violations of Article 14 were found. ${ }^{44}$ The concept of vulnerable groups was later crystallised in DH and Others $v$ the Czech Republic in 2007, a case concerning discrimination in the right to education by assigning Romani children disproportionately to specialised schools. The Court ruled in favour of the applicants and found that there had been a violation of Article 14. The Court viewed Roma individuals as a 'disadvantaged and vulnerable minority' on the basis of 'their turbulent history and constant uprooting. ${ }^{45}$ Hence, stated the Court, Roma individuals should be given 'special protection' and this protection should be extended to the field of education. ${ }^{46}$ Negative social attitudes toward the vulnerable group were also cited as a factor in determining vulnerable groups, according to the VC $v$ Slovakia case. ${ }^{47}$

Overall, social context is much considered in Article 14 cases, ${ }^{48}$ with negative social attitudes, dependency on the state, historical prejudice, and social exclusion identified as indicators of vulnerable groups. ${ }^{49}$ As of January 2021, the Court has explicitly addressed the vulnerability of applicants under Article 14 in approximately 33 judgments. ${ }^{50}$ The Court also considers that asylum seekers and HIV carriers are vulnerable groups. ${ }^{51}$ The vulnerability criterion has enabled the Court to examine different facets of inequality more substantively. ${ }^{52}$ The Court has been able to address complicated situations of disadvantage through a specific lens of vulnerability. In this vein, the vulnerability criterion has helped the Court to progress its Article 14 jurisprudence, particularly regarding positive obligations and

\footnotetext{
${ }^{37}$ Schabas, above n 11, pp 567-568.

${ }^{38}$ James and Others $v$ the United Kingdom Application No 8793/79, Merits and Just Satisfaction, 21 February 1986, at [46].

${ }^{39}$ Arnardóttir, above n 8, at 165 .

${ }^{40}$ Peroni and Timmer, above $\mathrm{n} 8$, at 1070.

${ }^{41}$ Arnardóttir, above $\mathrm{n} 8$, at 166 .

${ }^{42}$ Timmer, above $\mathrm{n} 5$, at 712 .

${ }^{43}$ Chapman $v$ the United Kingdom, above n 10, at [93], [96].

${ }^{44}$ Peroni and Timmer, above $\mathrm{n} 8$, at 1063.

${ }^{45} \mathrm{DH}$ and Others $v$ the Czech Republic, above n 6, at [182].

${ }^{46}$ Ibid.

${ }^{47}$ VC $v$ Slovakia Application No 18968/07, Merits and Just Satisfaction, 8 November 2011, at [146] and [179].

${ }^{48} \mathrm{OM}$ Arnardóttir 'The differences that make a difference: recent developments on the discrimination grounds and the margin of appreciation under Article 14 of the European Convention on Human Rights' (2014) 14 Human Rights Law Review 647 at 654.

${ }^{49}$ Peroni and Timmer, above $\mathrm{n} 8$, at 1070 .

${ }^{50}$ Arnardóttir, above n 8 , at 158; additional research conducted by the author in HUDOC, available at https://hudoc.echr. coe.int/eng\#\{\%22documentcollectionid2\%22:[\%22GRANDCHAMBER\%22,\%22CHAMBER\%22]\} (last accessed May 2021).

${ }^{51}$ Peroni and Timmer, above n 8 , at 1057.

${ }^{52}$ Ibid.
} 
indirect discrimination. ${ }^{53}$ Nonetheless, whether the vulnerability criterion has improved the effectiveness of Article 14 is questionable.

\section{Ineffectiveness of Article 14 in protecting vulnerable people against discrimination}

This section examines the situation both before and after the introduction of the concept of vulnerable groups. Through this division, this paper asserts that Article 14 has been continually ineffective in coping with discrimination against vulnerable groups, despite the Court's endeavours to improve.

\section{(a) Before the introduction of vulnerability criterion}

I first argue that the ineffectiveness of Article 14 is inherent in the provision itself and that the Court's inconsistency in Article 14 cases aggravated such ineffectiveness.

\section{(i) Parasitic nature of Article 14}

Due to the phrase 'rights and freedoms set forth in this Convention', Article 14 is known as a parasitic provision, as the article cannot operate without the other, substantive, articles. ${ }^{54}$ However, this is not entirely true. Article $14 \mathrm{can}$ be violated when there are no violations in other substantive articles. ${ }^{55}$ In the Belgian Linguistic case in 1968, the Court acknowledged the autonomous role of Article $14 .^{56}$

Apart from that case, however, the Court has mostly found Article 14 violations in conjunction with other substantive articles. As such, Article 14 has a functional limitation, as the Court does not rule a sole violation of Article 14 when the issues do not fall within the ambit of other substantive provisions. This is evident in the case of Botta $v$ Italy, which involved the effective access of disabled people to private buildings. ${ }^{57}$ The disabled are classified as a vulnerable group by the Court. ${ }^{58}$ Here, the applicant's complaint was based on Article 8, right to private life, and Article 14. However, the Court ruled both of the articles inadmissible in this case. ${ }^{59}$ In this process, the Court limited the autonomous character of Article 14, by stating that the article cannot be applied when the facts of the case do not fall within the ambit of the substantive provisions. ${ }^{60}$

This functional limitation of Article 14 was well-recognised in the international community, and led to the introduction of Protocol 12 for a free-standing provision on the prohibition of discrimination. ${ }^{61}$ Article 1 of Protocol 12 to the ECHR stipulates that 'the enjoyment of any right set forth by law shall be secured without discrimination on any ground'. ${ }^{62}$ This departs from the 'set forth in this Convention' approach taken by Article 14. Although this Protocol certainly improves the effectiveness of Article 14, as of May 2021 only 20 contracting parties to the ECHR have ratified the Protocol. ${ }^{63}$ As there are 47 Member States of the Council of Europe, this means that less than half of them have ratified the Protocol. Therefore, the parasitic character of Article 14 has not been fully modified by the Protocol, since the majority of the parties to the ECHR are still only bound by Article 14 .

\footnotetext{
${ }^{53}$ Arnardóttir, above n 8 , at 170 .

${ }^{54}$ Janis et al, above n 22, p 470.

${ }^{55}$ Harris et al, above n 16, p 784.

${ }^{56}$ Case Relating to Certain Aspects of the Laws on the Use of Languages in Education in Belgium, European Commission of Human Rights $v$ Belgium Application Nos 1474/62, 1677/62, 1691/62, 1769/63, 1994/63, and 2126/64, Merits and Just Satisfaction, 23 July 1968, p 25.

${ }^{57}$ Botta $v$ Italy Application No 21439/93, Merits and Just Satisfaction, 24 February 1998.

${ }^{58}$ Kiyutin v Russia Application No 2700/10, Merits and Just Satisfaction, 10 March 2011, at [48].

${ }^{59}$ Botta $v$ Italy, above $\mathrm{n} 57$, at $\mathrm{p} 13$.

${ }^{60}$ Ibid, at [39].

${ }^{61}$ Janis et al, above n 22, p 470.

${ }^{62}$ Article 1 of Protocol No 12 to the Convention for the Protection of Human Rights and Fundamental Freedoms (adopted 4 November 2020, entered into force 1 April 2005) ETS 177.

${ }^{63}$ Council of Europe 'Chart of signatures and ratifications of Treaty 177: Protocol No 12 to the Convention for the Protection of Human Rights and Fundamental Freedoms', 16 January 2021, available at www.coe.int/en/web/conventions/ full-list/-/conventions/treaty/177/signatures?p_auth=ITy78SGa (last accessed 10 May 2021).
} 


\section{(ii) Inconsistency in the court's judgments}

Scholars have pointed out the overall inconsistency in the Court's approach to Article 14 cases regardless of the applicants' vulnerable status. ${ }^{64}$ This inconsistency is dangerous and susceptible to arbitrary interpretation. Considering that it is the discriminated groups who would benefit from consistent adjudication on Article 14, coherent judgments on Article 14 are sorely needed. In this section, I explore the inconsistency shown in Article 14 judgments, particularly in how the Court has applied the comparator approach: (1) inconsistently in using or discarding the comparator approach, and (2) without internal guidelines on the selection of comparators.

First, there are a rising number of cases which discard the comparator approach entirely, raising scepticism about whether the comparator approach is essential in proving discrimination. ${ }^{65}$ In cases such as Bayev and Others $v$ Russia and DH and Others $v$ Czech Republic, no comparator was used to identify differential treatment and discrimination. ${ }^{66}$ Rather than selecting a comparator, focusing on less favourable treatment 'without proper justification' is a possible substitute for the comparator approach. ${ }^{67}$ The case of Carvalho Pinto de Sousa Morais v. Portugal discarded the comparator approach. ${ }^{68}$ In this case, where the applicant argued gender and age stereotypes, the Court did not set a Portuguese male as a comparator to examine differential treatment, unlike most of the case law. Rather, as the concurring opinion of Judge Yudkivska states, the Court found it a violation of Article 14 'where prejudicial stereotypes have affected the judicial assessment of evidence'. ${ }^{69}$ This judgment is not the only case to discard the comparator approach: cases such as Opuz $v$ Turkey and Volodina $v$ Russia also did not use a comparator to prove gender-based discrimination. ${ }^{70}$ Nevertheless, there are still voices who would like to resurrect the comparator approach to verify differential treatment, notably the dissenting opinion in the Carvalho Pinto de Sousa Morais v Portugal case. $^{71}$

Secondly, the Court does not follow any internal guidelines or procedures in applying the comparator approach. ${ }^{72}$ As mentioned above, many cases have not used the comparator approach, which demonstrates that it is not essential in Article 14 cases. ${ }^{73}$ Moreover, not all cases will have a clear-cut comparator to the applicant, in cases such as pregnancy and sex-based segregation in workforces. ${ }^{74}$ This inconsistency in judgments seems to be inevitable without internal guidelines on how to select the comparator.

The Court has mostly taken male, heterosexual, white, able-bodied Christian as a comparator to the applicant. ${ }^{75}$ Nevertheless, putting this comparator as a stereotype hinders substantive equality since

\footnotetext{
${ }^{64}$ Cartabia, above n 5, at 810; Gerards, above n 5, at 102.

${ }^{65} \mathrm{~S}$ Gurol 'Challenging gender stereotyping before the ECtHR: case of Carvalho Pinto v Portugal' (EJIL: Talk! 21 September 2017), available at www.ejiltalk.org/challenging-gender-stereotyping-before-the-ecthr-case-of-carvalho-pinto-vportugal/ (last accessed 10 May 2021).

${ }^{66}$ Bayev and Others $v$ Russia Application Nos 67667/09, 44092/12 and 56717/12, Merits and Just Satisfaction, 20 June 2017; DH and Others $v$ the Czech Republic, above n 6.

${ }^{67}$ Carvalho Pinto de Sousa Morais v Portugal Application No 17484/15, Merits and Just Satisfaction, 25 July 2017, at para [44].

${ }^{68} \mathrm{~L}$ Peroni 'Age and gender discrimination: laudable anti-stereotyping reasoning in Carvalho Pinto v Portugal' (Strasbourg Observers, 28 September 2017), available at strasbourgobservers.com/2017/09/28/age-and-gender-discrimination-laudableanti-stereotyping-reasoning-in-carvalho-pinto-v-portugal/ (last accessed 10 May 2021).

${ }^{69}$ Concurring Opinion of Judge Yudkivska, European Court of Human Rights, Carvalho Pinto de Sousa Morais v Portugal (App 17484/15, 25 July 2017), p 22.

${ }^{70} \mathrm{C}$ Danisi 'How far can the European Court of Human Rights go in the fight against discrimination? Defining new standards in its nondiscrimination jurisprudence' (2011) 9 International Journal of Constitutional Law 793 at 800; Opuz v Turkey Application No 33401/02, Merits and Just Satisfaction, 9 June 2009; Volodina v Russia Application No 41261/17, Merits and Just Satisfaction, 9 July 2019.

${ }^{71}$ Joint Dissenting Opinion of Judges Ravarani and Bošnjak, Carvalho Pinto de Sousa Morais v Portugal, above n 67.

${ }^{72}$ O'Connell, above n 12, at 217-218. None are stated in the Guide on Article 14 of the European Convention on Human Rights and on Article 1 of Protocol No 12 to the Convention, above n 24.

${ }^{73}$ For example, DH and Others $v$ the Czech Republic, above n 6; Bayev and Others $v$ Russia, above n 66.

${ }^{74}$ O'Connell, above n 12 , at 217-218.

${ }^{75}$ Ibid, at 228.
} 
this demands that the applicant be treated similarly to a comparator who is in different circumstances. In other words, this approach asks different individuals to be treated similarly, running counter to the spirits of substantive equality. This is further related to the weakness of the comparator approach that traps the Court in the 'sameness/difference ideology.' ${ }^{76}$ Timmer argues that the Court should rather pay attention to more substantive issues 'such as whether her dignity was breached, or whether the rule perpetrates subordination of a vulnerable group' ${ }^{77}$ The comparator approach blurs the focus of the Court in dealing with discrimination cases, as the Court tends to focus on the 'social stratification' rather than traits themselves. ${ }^{78}$

Moreover, the outcome of cases is greatly swayed by which comparator the Court chooses. In Gas and Dubois $v$ France, an adoption order was at stake for the applicants who were same-sex couples, a vulnerable group according to the Court. ${ }^{79}$ The applicants alleged that the prohibition on providing adoption orders to unmarried couples was discriminating against the applicants based on sexual orientation, because France at the time prohibited the marriage of same-sex couples. ${ }^{80}$ On the other hand, the French government argued that it was difficult to take other steps without involving Parliament, as there had not yet been a debate on parental responsibility in France. ${ }^{81}$ Although this case was prima facie concerned with adoption orders for unmarried couples, in essence it was relevant to same-sex marriage.

The applicant argued that the comparator here should be a married heterosexual couple, but the Court took an unmarried heterosexual couple as a comparator. ${ }^{82}$ According to the Court, since unmarried couples are not eligible for adoption orders, like the applicants, there was no differential treatment of the applicants. Therefore, the Court ruled that France did not violate Article $14 .^{83}$ The Court, via this logic, circumvented the debate on same-sex marriage by focusing on the marriage rather than homosexuality in choosing the comparator.

However, unmarried heterosexual couples can marry under Article 144 of the French Civil Code and then pursue an adoption order. The applicants and unmarried heterosexual couples are in fact treated differently, as the latter have a route to follow if they want an adoption order. This case shows that the choice of a comparator may entirely change the course of the case. Whether there has been a differential treatment is dependent on who the comparator is. Considering that the cases of Karner $v$ Austria and Kozak $v$ Poland have explicitly recognised sexual orientation to be included in grounds of discrimination, ${ }^{84}$ the Court seems to not extend this to the realm of adoption. ${ }^{85}$ This nature of comparator approach shows that the Court is arbitrarily choosing the comparator to justify its legal reasoning.

\section{(b) After the introduction of the vulnerability criterion}

The Court introduced the vulnerability criterion to overcome these shortcomings. Notwithstanding the intention, the criterion has also raised substantial criticism about whether it properly tackles discrimination against vulnerable groups. This section delves into the ineffectiveness of the Court's focus on the vulnerability of the applicants in three areas: the ambiguous concept of vulnerable groups; inconsistency within vulnerable group cases; and stigmatisation and paternalism of the concept.

\footnotetext{
${ }^{76}$ Timmer, above n 32.

${ }^{77}$ Ibid.

${ }^{78}$ Ibid.

${ }^{79}$ Kiyutin v Russia, above n 58.

${ }^{80}$ Gas and Dubois v France Application No 25951/07, Merits and Just Satisfaction, 15 March 2012, at [27], [42].

${ }^{81}$ Ibid, at [52].

${ }^{82}$ Ibid, at [69].

${ }^{83}$ Ibid, at [69]-[73].

${ }^{84}$ Karner v Austria Application No 40016/98, Merits and Just Satisfaction, 24 July 2013, at [37]; Kozak v Poland Application No 13102/02, Merits and Just Satisfaction, 2 March 2010, at [92].

${ }^{85} \mathrm{P}$ Johnson Homosexuality and the European Court of Human Rights (Routledge, 2013) p 132.
} 


\section{(i) Ambiguous concept of vulnerability}

The Court's ill-defined adoption of the vulnerability criterion leads to further confusion about the definition and range of 'vulnerable groups'. This section explores the concept of vulnerability advanced by vulnerability theorists and compares this with the Court's conceptualisation of vulnerability.

The Court has the same objective as the vulnerability theorists, ie protecting vulnerable individuals. However, the Court applies the concept more selectively, which renders the concept more ambiguous. Without clearly defining what 'vulnerability' means, the Court's vulnerability criterion is prone to expand universally, which conflicts with the need for special protection for vulnerable individuals.

The Cambridge Dictionary defines 'vulnerable' as 'able to be easily physically, emotionally, or mentally hurt, influenced, or attacked'. ${ }^{86}$ Hoffmaster builds the definition of vulnerability from Whitehead's definition of a human being. According to Hoffmaster, vulnerability is a loss to three urges of being a human: losses '(1) to live, (2) to live well, and (3) to live better'. ${ }^{87}$ The vulnerability literature expands and classifies vulnerability into two sources and states of vulnerability. ${ }^{88}$ First, the two sources of vulnerability are inherent and situational. ${ }^{89}$ Inherent vulnerability involves the innate sources of vulnerability arising from the human condition. Fineman's definition of vulnerability well incorporates this inherent sense of vulnerability: 'the continuous susceptibility to change in both our bodily and social well-being that all human beings experience. ${ }^{90}$ Situational vulnerability, on the other hand, refers to sources of vulnerability which are caused or aggravated by personal, social, political, economic, or environmental situations. As such, situational vulnerability is more context dependent. ${ }^{91}$ There is a subset of situational vulnerability, pathogenic vulnerability, which involves 'particularly ethically troubling' sources, such as 'morally dysfunctional or abusive interpersonal and social relationships and sociopolitical oppression or injustice'. ${ }^{92}$

Secondly, the two states of vulnerability are dispositional and occurrent. These two states refer to potential or actual vulnerabilities. ${ }^{93}$ For example, all children are dispositionally vulnerable unless they are regularly and properly cared for (potential vulnerabilities). In contrast, whether these children will be occurrently vulnerable is dependent on various factors: lack of parental or social care, accidents, physical or emotional abuse, and so forth (actual vulnerabilities).

Vulnerability theory focuses on the institutional structure and mechanisms resulting in inequality. For example, there is an inherently unequal relationship between parent and child or employer and employee which comes with different levels of authority and power. ${ }^{94}$ The vulnerability theory expands this to all social relations and argues that a legal subject should be defined by its vulnerability and dependency, rather than exclusively by liberty or rationality. ${ }^{95}$ In this vein, human rights law has evolved thanks to 'the dynamic and dialectical relationship between institutional precariousness and ontological vulnerability'. ${ }^{96}$

The Court has not provided any definition of vulnerability or 'vulnerable group'. Instead, it has identified the markers of vulnerability, namely social disadvantages, dependence on the state, and

\footnotetext{
${ }^{86}$ 'Vulnerable', Cambridge Dictionary, available at https://dictionary.cambridge.org/dictionary/english/vulnerable (last accessed 10 May 2021).

${ }^{87}$ AN Whitehead The Function of Reason (Boston, Mass: Beacon Press, 1929) p 8; B Hoffmaster 'What does vulnerability mean?' (2006) 36 Hastings Center Report 38 at 42.

${ }^{88} \mathrm{C}$ Mackenzie et al 'Introduction' in C Mackenzie et al (eds) Vulnerability: New Essays in Ethics and Feminist Philosophy (Oxford: Oxford University Press, 2013) p 1 at p 7.

${ }^{89}$ Ibid, p 9.

${ }^{90}$ MA Fineman 'Vulnerability and inevitable inequality' (2017) 4 Oslo Law Review 133 at 142.

${ }^{91}$ Mackenzie et al, above n 88 , p 7.

${ }^{92}$ Ibid, p 9.

${ }^{93}$ Ibid, p 8.

${ }^{94}$ Fineman, above $\mathrm{n} 90$, at 135.

${ }^{95}$ MA Fineman 'Vulnerability and social justice' (2019) 53 Valparaiso Law Review 341 at 356 . Hoffmaster also argues that vulnerability is more a basic feature of humans than rationality: Hoffmaster, above $\mathrm{n} 87$, at 43 .

${ }^{96}$ BS Turner Vulnerability and Human Rights (University Park: Pennsylvania State University Press) p 32.
} 
historical prejudice and stigmatisation, which suggest that groups may fall into this category. ${ }^{97}$ For instance, other national and religious minorities can also be classified as vulnerable groups. ${ }^{98}$ What is different from vulnerability theory is that the Court's application of the vulnerability criterion is selective, whereas the theory applies universally. Whilst the Court demands that the respondent state provide special protection to the vulnerable groups, the theorists argue that everyone should be deemed vulnerable to institutional structures and changes. The Court's approach to vulnerability, therefore, greatly diverges from the theoretical approach to the concept.

Despite this selective approach to who is vulnerable, the spectrum of vulnerable groups is prone to be applied expansively by the Court. As the vulnerability theory points out, everyone is inherently and situationally vulnerable in front of the respondent states, due to their supreme power and authority over individuals. This possibility of expansion also partially stems from the fact that the Court has not defined 'vulnerability'. From what Court ruled to be 'vulnerable groups', it encompasses groups where the discrimination rises from both inherent sources of vulnerability (disabled persons) and situational sources of vulnerability (racial discrimination). These two sources are not mutually exclusive: for example, a person with a mobility impairment may have slower responsiveness to fast-moving vehicles. This person is also exposed to situational sources of vulnerability, such as social discrimination toward the person's impairment. ${ }^{99}$ Nonetheless, with the Court being silent on an exact definition of 'vulnerability', it is perhaps inevitable for Article 14 jurisprudence to slowly embody more and more sources of vulnerability.

As the Court expands the spectrum of vulnerable groups, the respondent state's 'special protection' of vulnerable groups may turn out to be no longer very special. A case which illustrates the possibility of endless expansion of 'vulnerable groups' is MSS $v$ Belgium and Greece, where the Court acknowledged asylum seekers as a vulnerable group. ${ }^{100}$ This was a departure from previous case law, as asylum seekers have not suffered from historical prejudices and with social exclusion (this is also mentioned in the separate opinion on this case). ${ }^{101}$ Asylum seekers, as a group, do not share a common history of turbulence and social exclusion, as they are of different nationalities. Each asylum seeker goes through different experiences of being vulnerable as a migrant. ${ }^{102}$ This complicates the conceptualisation of vulnerable groups: it is doubtful whether they can be grouped as one, as the Court's indicator might suggest. ${ }^{103}$ In light of the Covid-19 crisis, this reasoning might extend to those who suffer aftereffects and social exclusion as Covid-19 patients, as they might be recognised to be vulnerable. If the rest of the case law follows this logic, one can insist that everyone is a member of at least one vulnerable group.

Conversely, some advocates of the majority opinion of the case assert that members of vulnerable groups do not have to display the same characteristics as a homogeneous group. ${ }^{104}$ Some highlight the past and present disadvantages which the applicants' group have suffered. ${ }^{105}$ Others underline the inequality produced by the social processes against asylum seekers. ${ }^{106}$ This reasoning on the expansion of the vulnerability criterion is rather closer to how the vulnerability theorists would have envisioned the application of the criterion - the ontological vulnerability of individuals.

\footnotetext{
${ }^{97}$ Peroni and Timmer, above n 8, at 1070.

${ }^{98}$ Ibid.

${ }^{99}$ JL Scully 'Disability and vulnerability: on bodies, dependence, and power' in Mackenzie et al, above n 88, pp 207-208.

${ }^{100}$ MSS v Belgium and Greece Application No 30696/09, Merits and Just Satisfaction, 21 January 2011, at para [251].

${ }^{101}$ Partly Concurring and Partly Dissenting Opinion of Judge Sajó, MSS v Belgium and Greece, above n 100, p 101-102.

${ }^{102}$ Baumgärtel, above n 8 , at 19 .

${ }^{103}$ Partly Concurring and Partly Dissenting Opinion of Judge Sajó, MSS v Belgium and Greece, above n 100, p 102.

${ }^{104}$ L Peroni 'MSS v Belgium and Greece: when is a group vulnerable?' (Strasbourg Observers, 10 February 2011), available at https://strasbourgobservers.com/2011/02/10/m-s-s-v-belgium-and-greece-when-is-a-group-vulnerable/ (last accessed 10 May 2021).

${ }^{105}$ Ibid.

${ }^{106}$ Baumgärtel, above n 8 , at 20.
} 
Nevertheless, recent cases indicate that the Court has started to acknowledge the backfiring consequences of the vulnerability criterion and has discarded the vulnerability criterion in some cases. For example, in the Grand Chamber Judgment of Calvalho Pinto de Sousa Morais v Portugal, the vulnerability criterion was not applied even though the issue of the case (gender violence) was a traditional field where the vulnerability approach has been used. ${ }^{107}$ Other cases since 2017, involving Roma and Muslims, also did not mention the vulnerability of the applicants, although third-party interveners commented during the proceedings that the applicants were vulnerable victims. ${ }^{108}$ However, the Court has not completely abandoned the vulnerability criterion: guidance published by the Court states that the Court should give a narrow margin of appreciation to individuals identified as a vulnerable group. ${ }^{109}$ In this vein, the next section examines how the vulnerability criterion has been inconsistently invoked by the Court and how the Court has applied the vulnerability criterion to reduce the margin of appreciation.

\section{(ii) Incoherent application of the vulnerability criterion}

Problems with the Court's approaches to Article 14 have intensified as a result of the vulnerability criterion being inconsistently invoked. Although there are cases which deal with identical vulnerable groups, the Court has not applied their 'vulnerability' criterion consistently. ${ }^{110}$ Those cases not mentioning vulnerability either followed the classic approach of Article 14 or mentioned the stereotype applicants faced. In some of these cases, the Court narrowed the margin of appreciation of the respondent state without mentioning the applicant's vulnerability. ${ }^{111}$ In other words, the outcome of some cases was the same even when an applicant's vulnerability was not invoked, which raises doubts about the usefulness of the vulnerability criterion.

Take an example of groups being discriminated based on their sexual orientation. Gas and Dubois $v$ France, Zhdanov and Others $v$ Russia, and Aghdgomelashvili and Japaridze v Georgia did not mention that the applicants belonged to vulnerable groups, although they were considered as vulnerable groups according to Kiyutin $v$ Russia. ${ }^{112}$ This is quite surprising, since the Kiyutin $v$ Russia (2011) preceded the other cases $(2012,2018$, and 2020 respectively). This raises the question of why the later cases did not follow the 'vulnerable' approach.

In several cases where the Court has mentioned the vulnerability of the applicants, it has been seemingly arbitrary about whether to narrow the margin of appreciation based on the vulnerability criterion, even after recognising the applicant's vulnerability. This is also observed in the classic example of a vulnerable group - the Roma. Since DH and Others $v$ the Czech Republic, the case which crystallised the vulnerability criterion on the education of Romani children, the Roma peoples have been the classic example of a vulnerable group. Likewise, in Burlya and Others $v$ Ukraine the Court mentions that the applicants were members of a vulnerable group, ie Roma. ${ }^{13}$ The applicants, Roma individuals living in Ukraine, were attacked by local residents after the murder of Ukrainian boy, allegedly by a Romani. However, the fact that the applicants were part of a vulnerable group was not used to narrow the respondent state's margin of appreciation. Instead, the Court simply mentioned that what the applicant suffered was degrading treatment as a member of a vulnerable group. ${ }^{114}$

\footnotetext{
${ }^{107}$ Arnardóttir, above n 8, at 161 .

${ }^{108}$ Alković v Montenegro Application No 66895/10, Merits and Just Satisfaction, 5 December 2017, at [62]; MF v Hungary Application No 45855/12, Merits and Just Satisfaction, 5 March 2018, [64].

${ }^{109}$ Guide on Article 14 of the European Convention on Human Rights and on Article 1 of Protocol No 12 to the Convention, above n 24, para 164 .

${ }^{110}$ Arnardóttir, above n 48 , at 654 .

${ }^{111}$ Zhdanov and Others $v$ Russia Application Nos 12200/08, 35949/11 and 58282/12, Merits and Just Satisfaction, 16 July 2019, at [179].

${ }^{112}$ Kiyutin v Russia, above n 58; Gas and Dubois v France, above n 80; Zhdanov and Others v Russia, above $\mathrm{n} 111$; Aghdgomelashvili and Japaridze v Georgia Application No 7224/11, Merits and Just Satisfaction, 8 October 2020.

${ }^{113}$ Burlya and Others $v$ Ukraine Application No 3289/10, Merits and Just Satisfaction, 6 November 2018, at [134].

${ }^{114}$ Ibid.
} 
When the Court did not invoke the vulnerability criterion at all, they either used the classical approach to Article 14 or the stereotype approach. In Zhdanov and Others $v$ Russia, the applicants were discriminated against when forming a non-profit organisation to promote LGBT rights. Rather than highlighting the applicants' vulnerability, the Court emphasised that sexual orientation belongs to the suspect categories. The Court then narrowed the margin of appreciation and required the respondent state, Russia, to provide substantial reasons to justify the differential treatment. ${ }^{115}$ As regards applicants being discriminated against due to their sexual orientation, this has been a classic example of a vulnerable group. However, the Court discarded the vulnerability criterion in this case, but adhered to the classical approach to Article 14.

Rather than discussing the vulnerability of the vulnerable groups, some cases focused on the negative social stereotype of the applicant's identity. ${ }^{116}$ This was found in Konstantin Markin $v$ Russia, where a shorter period of parental leave than the maternal leave was at stake. ${ }^{117}$ The majority opinion here did not mention the vulnerability of women but rather circumvented this by condemning genderbased stereotypes. ${ }^{118}$ In particular, the judgment criticised the historic stereotype of women which assumes that they have the primary role in raising children. ${ }^{119}$ Furthermore, differential treatment based on these gender-based stereotypes was insufficient to amount to reasonable justification by Russia. ${ }^{120}$ This stereotype approach was echoed in Khamtokhu and Aksenchik $v$ Russia. ${ }^{121}$

The Court's approach through the stereotype is rather odd, as an emphasis on vulnerability and stereotype are both based on the historical suffering of the groups and negative social perception. Similar to the vulnerability approach, the Konstantin Markin $v$ Russia case also mentions the historical disadvantage of women, acknowledging the necessity of mitigating such disadvantage. ${ }^{122}$ Likewise, cases such as $V C v$ Slovakia report negative social attitudes toward Roma individuals when mentioning vulnerable groups. ${ }^{123}$ Considering that these two approaches have their foundation in both discriminated history and negative social perception, it is peculiar that the Court chose to use different terminologies in dealing with analogous cases.

\section{(iii) Stigmatisation of vulnerable groups and paternalism}

Grouping the applicants as 'vulnerable' and requiring special protection for them can lead to paternalism. This section explores the Court's paternalism in Article 14 cases with the vulnerability criterion and argues that this paternalism stems from the use of 'vulnerability'. The paternalism of the Court can be demonstrated by the famous $D H$ and Others $v$ the Czech Republic case, where Romani people were described as a 'disadvantaged and vulnerable minority. ${ }^{124}$ The problem with such stigmatisation is that it is used to correct formal equality, not substantive equality. Such an approach rather undermines substantive equality, by classifying and stigmatising certain groups as vulnerable. Rather than being viewed as individuals, the applicants are labelled as a member of a particular group by the Court. ${ }^{125}$

This labelling may further result in paternalism, as is evident from the DH and Others $v$ the Czech Republic case. The judgment states that 'the Court is not satisfied that the parents of the Roma children, who were members of a disadvantaged community and often poorly educated, were capable of weighing up all the aspects of the situation and the consequences of giving their consent'. ${ }^{126}$ Although

\footnotetext{
${ }^{115}$ Zhdanov and Others $v$ Russia, above $\mathrm{n} 111$, at [179].

${ }^{116}$ Arnardóttir, above n 8 , at 160 .

${ }^{117}$ Konstantin Markin v Russia Application No 30078/06, Merits and Just Satisfaction, 22 March 2012.

${ }^{118}$ Ibid, at para 99.

${ }^{119}$ Arnardóttir, above $\mathrm{n} 8$, at 160 .

${ }^{120}$ Konstantin Markin v Russia, above n 117, at [143].

${ }^{121}$ Khamtokhu and Aksenchik v Russia Application Nos 60367/08 and 961/11, Merits and Just Satisfaction, 24 January 2017, at [50].

${ }^{122}$ Konstantin Markin v Russia, above n 117, at [104].

${ }^{123}$ VC $v$ Slovakia, above n 47, at [146], [179].

${ }^{124} \mathrm{DH}$ and Others $v$ the Czech Republic, above n 6, at [182].

${ }^{125}$ Peroni and Timmer, above n 8, at 1064.

${ }^{126} \mathrm{DH}$ and Others $v$ the Czech Republic, above n 6, at [204].
} 
this is guided by good intentions, as Judge Borrego Borrego comments, this indicates not only paternalism but also an authoritarian attitude. ${ }^{127}$ In other words, the judgment is implying that it is the judges, rather than the Romani parents, who are more able to decide which schools Roma children should attend. The paternalistic tone of the Court in dealing with the vulnerable groups' cases has been also explicitly condemned. In Khamtokhu and Aksenchik $v$ Russia, the Equal Rights Trust tackled the Court's underlying perception that women need protection, as they are more vulnerable than men as a third party. ${ }^{128}$

The Court's paternalism is inevitable as long as the Court invokes the vulnerability criterion. This is because the Court demands the respondent state to provide 'special protection' to the group which the vulnerable applicant belongs to. This is a common trap to fall into when facing a vulnerable individual - when someone is vulnerable to serious harm, it is unobjectionable to think in terms of trying to protect them. Despite the good intention, when this protection is elevated to the level of social intervention, it may cause a pathogenic source of vulnerability, with 'the relationships of domination and inequality among members of a community or between the state and citizens' being perpetuated. ${ }^{129}$ The Court's grouping and labelling rather undermine substantive equality, by classifying and stigmatising certain groups as vulnerable. Rather than being viewed as individuals, the applicants are labelled as a member of a particular group by the Court. ${ }^{130}$ This may negatively reinforce the stereotypical images of the group, reproducing further disadvantage. ${ }^{131}$ It is also paradoxical to label them with a special status, 'vulnerable group', for the sake of equal treatment. The Court must be reminded that the applicants did not ask for the 'special protection' of the respondent state. The applicants were asking for no unjustified discrimination based on their different circumstances.

The Court also has failed to provide a non-paternalistic form of protection to vulnerable individuals. Smiley sets three criteria for a non-paternalistic form of protection: (1) the protection should receive universal support from all individuals; (2) the protection should be conceived as applying to all individuals, rather than specific individuals or groups, and; (3) the protection should not give government officials any power to control the protected individuals. ${ }^{132}$ The Court has failed to meet the first two criteria: for the first criterion, the Court is imposing the protection on the respondent state without considering the domestic consensus on such protection. The second criterion also failed to be met, as only individuals identified as being in the 'vulnerable group' by the Court will be provided with the special protection.

In this vein, the Court's use of the vulnerability criterion had the inevitable consequence of paternalism, as is evident from the Article 14 jurisprudence. Fortunately, in VC v Slovakia, the Court acknowledged the dangers of paternalism when condemning the acts of hospital staff. ${ }^{133}$ Though the case was concerned with the forced sterilisation of Romani women without the informed consent of the patients, the Court stated that autonomy of patients also required respect for 'a person's dignity and integrity'. ${ }^{134}$ In Burlya and Others $v$ Ukraine, the Court used the applicants' dignity as a means of deciding whether they went through degrading treatment as Romani people. ${ }^{135}$ Such language of the Court in discussing the vulnerable groups is laudable, with the focus on the individuals rather than the individual within a group. Nonetheless, the fact that this approach is not universal in the Court's case law means that the Court must acknowledge that paternalism is another form of discrimination, undermining substantive equality.

\footnotetext{
${ }^{127}$ Dissenting Opinion of Judge Borrego Borrego, DH and Others $v$ the Czech Republic, above n 6, at [14], [15].

${ }^{128}$ Khamtokhu and Aksenchik $v$ Russia, above $\mathrm{n} \mathrm{121,} \mathrm{at} \mathrm{[50].}$

${ }^{129} \mathrm{C}$ Mackenzie 'The importance of relational autonomy and capabilities for an ethics of vulnerability' in Mackenzie et al, above $\mathrm{n} 88, \mathrm{p} 33$ at $\mathrm{p} 47$.

${ }^{130}$ Peroni and Timmer, above $\mathrm{n} 8$, at 1064 .

${ }^{131}$ Arnardóttir, above n 8, at 168 .

${ }^{132} \mathrm{M}$ Smiley 'Paternalism and democracy' (1989) 23 The Journal of Value Inquiry 299 at 312.

${ }^{133}$ Peroni and Timmer, above $\mathrm{n} 8$, at 1073 .

${ }^{134}$ VC $v$ Slovakia, above n 47, at [115].

${ }^{135}$ Burlya and Others $v$ Ukraine, above n 113, at [134].
} 


\section{Departing from the vulnerability criterion}

The principal issue of concern Article 14 cases has been inconsistency. In general, the Court has approached Article 14 cases by examining: (1) whether the allegation falls within the ambit of other substantive provisions; (2) whether there has been discriminatory treatment; and (3) if the treatment is proved to be discriminatory, whether the respondent state can provide reasonable justification for it. The Court has invoked a vulnerability criterion either in choosing a comparator in stage (2) or in narrowing the margin of appreciation in stage (3). However, this practice has differed greatly depending on the case. The legal reasoning after applying the comparator or vulnerability criterion has been in disarray too. This inconsistency undermines the stability and predictability of European human rights case law. What is more fatal is that these arbitrary rulings weaken the Court's legitimacy.

In this situation, this paper recommends the that Court prioritise individual identity over group identity, by departing from the vulnerability criterion. The Court should instead emphasise how the discriminatory treatment undermined the applicants' autonomy. Social stratification needs to be mentioned only in terms of where the grounds of discrimination lie, not in deciding the respondent state's margin of appreciation. The Court must also take into account the theoretical discussions on how to treat individuals. Avoiding grouping and treating individuals equally have already been actively discussed in the discrimination literature.

The focus on the applicant's autonomy stems from the Court's moral and political obligation towards vulnerable people. The fact that people are inherently and situationally vulnerable gives rise to moral and political obligations to assist people who are occurrently vulnerable and also to reduce and prevent the risks of dispositional vulnerabilities being actualised. ${ }^{136}$ This paper argues that the Court should focus on the applicant's autonomy when responding to vulnerability, in order to foster equality.

Some theorists deem autonomy to be inappropriate in approaching vulnerable individuals Fineman argues that autonomy is inimical to tackling vulnerability because autonomy erases structural injustice but instead highlights individual responsibility rather than an institutional one. ${ }^{137}$ This may be true in the inherent vulnerability, which involves inescapable ontological vulnerabilities we may have. ${ }^{138}$ However, unlike Fineman's model, the Court's objective in Article 14 is to correct the situational and occurrent vulnerability, rather than the inherent vulnerability. An applicant brings the case to the Court when a respondent state's discriminatory treatment (situational source) has already happened (occurrent state). The Court's responsibility in this would be to identify the situational source of the vulnerability to correct the occurrent state. As an example, the Court would tackle society's discriminative response to disabled people (situational source), rather than tackling the disability itself (inherent source). However, this is not to say that the Court is not interested at all in inherent the sources of vulnerability. As mentioned above, the Court identifies specific ethnic individuals to be in a vulnerable group, which necessitates that the applicant be born with that specific ethnicity (inherent source). Nonetheless, the Court's role is to minimise and compensate for the discrimination in society rather than to change the applicant's ethnicity itself.

In order to respond to groups that are vulnerable to discrimination, the Court should aim to foster autonomy, rather than demanding 'special protection' for them. This is to first, respond to the vulnerable individuals' loss of agency, and secondly, to counter the paternalism often associated with the vulnerability discourse. ${ }^{139}$ Since discrimination stems from a disregard for a person's autonomy in their life and associating them with grounds of discrimination, the Court should attempt to restore the demeaned autonomy. This is because the autonomy differentiates people from each other based on their choices and actions. ${ }^{140}$ Respecting individuals' autonomy primarily involves allowing

\footnotetext{
${ }^{136}$ Mackenzie et al, above n 88, p 8.

${ }^{137}$ Fineman, above $\mathrm{n} 90$, at 141-142; Hoffmaster also argues that autonomy is an individualistic ideal, therefore antithetical to vulnerability: Hoffmaster, above n 87 , at 42 .

${ }^{138}$ Mackenzie, above n 129, p 37.

${ }^{139}$ Ibid, p 45.

${ }^{140}$ BA Eidelson Discrimination and Disrespect (Oxford: Oxford University Press, 2015) p 138.
} 
individuals to shape their own lives. When discriminatory treatment arises, the individuals' values and ways of life should be considered in assessing the wrongful interference. ${ }^{141}$

But what exactly is autonomy and how will this approach blend with the Court's Article 14 jurisprudence? Autonomy has two facets: first, a person's capacity to decide the path of their life; secondly, for a person to be recognised as an autonomous agent by the others. ${ }^{142}$ With regard to the first of these, the Court should not only aim to provide more options for vulnerable individuals, but also be concerned with the social distribution of opportunities and whether the citizens 'have an adequate range of genuine and significant options available to them'. ${ }^{143}$ This perspective of autonomy is distinct from the libertarian concept of autonomy, which underlines 'one's control over one's circumstances'. ${ }^{144}$ This libertarian view of autonomy often erases the social contexts which result in the available options. The Court should, therefore, consider not only how the applicant would have exercised their autonomy, ${ }^{145}$ but also how the societal distribution of opportunities has narrowed down the applicant's options in the first place. ${ }^{146}$

On autonomy as a status, this aspect focuses on the social dimension of autonomy, which also relies on the social and interpersonal recognition between individuals. Being a fluent English speaker requires one's interpersonal interactions to not only learn the linguistic aspect, but also to master the social practices accompanied by the language. This aspect of autonomy is distinct from the physical aspect of autonomy and can be extended to how one adapts into a society. Being a member of society requires intersubjective experience, so that one can be an autonomous agent in society. ${ }^{147}$ This approach to autonomy will enable the Court to also tackle structural discrimination that the applicants are facing, by considering how the vulnerable individuals are recognised in the respondent state's society.

In deciding how the applicant has been discriminated against, the Court may examine how the respondent state interfered with the applicant's autonomy without reasonable justification. In this way, the Court does not have to resort to the same grounds as the grounds of discrimination: the group affiliation. This modified approach would not fundamentally change the nature of Article 14, which is to prohibit discrimination. The autonomy approach would also not deny the structural injustice faced by the applicants. The grounds of discrimination will be mentioned in the Court's judgments but the Court will not ask the respondent state for 'special protection' or contrast their group affiliations with a comparator. In this process, the Court can also explore how structural injustice has curtailed the autonomy of the applicants and others who share the same characteristics of discrimination. In this way, the Court can also tackle the structural injustice without grouping the applicants.

\section{Conclusion}

Despite the vigorous efforts of the Court to overcome the innate constraints of Article 14, the provision has been ineffective in protecting disadvantaged and vulnerable groups. Before special consideration for vulnerable groups was introduced by the Court, Article 14 struggled to protect these groups due to the parasitic character of the provision and inconsistent application by the Court. With the advent of the vulnerability criterion, the Court asserted the necessity of special protection for the vulnerable groups and allowed a narrower margin of appreciation to the respondent state. Yet, this led to another form of ineffectiveness for Article 14. This involved: ambiguous conceptualisation; the inconsistent application of the vulnerability criterion; and stigmatisation and paternalism with regard to vulnerable

\footnotetext{
${ }^{141}$ BA Eidelson 'Treating people as individuals' in D Hellman and S Moreau (eds) Philosophical Foundations of Discrimination Law (Oxford: Oxford University Press, 2013) p 203 at p 214.

${ }^{142}$ Mackenzie, above n 129, p 41.

${ }^{143}$ Ibid, p 45.

${ }^{144} \mathrm{~J}$ Anderson 'Autonomy and vulnerability entwined' in Mackenzie et al, above n 88, p 134 at p 137.

${ }^{145}$ Eidelson, above n 141 , at 216.

${ }^{146}$ Mackenzie, above n 129, p 45.

${ }^{147}$ Anderson, above n 144, p 139.
} 
groups. The Court may have introduced such concepts with the best of intentions, to correct the inequality. However, such special consideration has stigmatised the discriminated groups as 'vulnerable' and has failed to treat the applicants as individuals.

To overcome these limitations, I recommended that the Court adopt the autonomy approach and discard the vulnerability criterion. By measuring how the respondent state limited a person's autonomy, the Court does not need to invoke the group affiliation which was also the foundation of the respondent state's discrimination. This ensures a better way of protecting 'les vulnérables' from grouping and labelling by both the respondent state and the Court. This change will also enable the Court to step closer to substantive equality, with applicants who have been discriminated against viewed as individuals rather than as members of vulnerable groups.

Cite this article: Kim SY (2021). Les vulnérables : evaluating the vulnerability criterion in Article 14 cases by the European Court of Human Rights. Legal Studies 41, 617-632. https://doi.org/10.1017/lst.2021.21 